\title{
Formação reflexiva de professores em Astronomia: indicadores que contribuem no processo ${ }^{+*}$
}

Rodolfo Langhi ${ }^{3}$

Departamento de Física - UNESP

Programa de Pós-Graduação em Educação para a Ciência - UNESP

Bauru - SP

Fabiana Andrade de Oliveira ${ }^{3}$

Doutoranda do Programa de Pós-Graduação em Educação para a Ciência UNESP

Polo Astronômico Casimiro Montenegro Filho

Janer Vilaça ${ }^{3}$

Polo Astronômico Casimiro Montenegro Filho

Fundação FPTI/BR

Foz do Iguaçu - PR

\section{Resumo}

Resultados de pesquisas frequentemente apontam sobre as problemáticas referentes ao ensino da Astronomia e suas relações com a formação inicial de professores. Em vista disso, cursos denominados de "formação continuada" são criados visando suprir estas lacunas formativas, porém, sob uma abordagem predominantemente conteudista, não proporcionando uma mudança efetiva da prática profissional do professor. Objetivamos, assim, sinalizar a superação deste modelo formativo conteudista identificando indicadores que se apresentaram como contribuintes para uma formação de professores sob abordagens reflexivas, conduzindo a possíveis mudanças em sua atuação em relação ao ensino da Astronomia. Estes indicadores foram constituídos a partir da Análise de Conteúdo de excertos de respostas de professores participantes de um pro-

\footnotetext{
${ }^{+}$Reflective training teachers in Astronomy: indicators that contribute in the process

* Recebido: maio de 2017. Aceito: maio de 2018.

${ }^{1}$ Parte deste artigo foi apresentada no XVI Encontro de Pesquisa em Ensino de Física - EPEF.

2 Apoio: Programa de Bolsa do PTI - C\&T+I/FPTI-BR.

3 E-mails: prof.langhi@gmail.com; anafabi.ufms@gmail.com; janer@pti.org.br
} 
grama de formação continuada e apontam para três etapas do processo reflexivo, a saber: reconhecimento sobre a importância de ensinar Astronomia, identificação de problemáticas intrínsecas e extrínsecas que podem interferir neste processo e, finalmente, mudança de postura quanto a ensinar Astronomia.

Palavras-chave: Educação em Astronomia; Formação de Professores; Análise de Conteúdo.

\begin{abstract}
Researches point to problems of the Astronomy teaching related with factors of the initial training of teachers. Then, some non-formal establishments offer courses called "continuing education" to improvement the Astronomy Education and supply these gaps. However, research results point that these formative moments are predominantly based only in contents and has not provided a change practice teacher. Our objective in this investigation is understand how overcome this model. So, this study sought by indicators what are presented as contributors to teacher training under reflective approaches, with an effective change in the practice of teachers to Astronomy at school. These indicators were constituted from the Content Analysis of the discourses of teachers during a continuous formation and point to three phases of this reflexive process: the teachers recognize the importance of Astronomy teaching, they identify their intrinsic and extrinsic problems and they change their actions to teach Astronomy.
\end{abstract}

Keywords: Astronomy Education; Teacher Formation; Content Analysis.

\title{
I. Fundamentação
}

É consenso da maioria dos pesquisadores da área de ensino de Ciências e de Física a existência de limitações oriundas da formação inicial de professores (BRASIL, 2002; LANGHI; NARDI, 2012). Por exemplo, mostrando resultados de avaliações sobre a formação inicial, Garcia (1999) apresenta diversos relatos negativos da parte de professores principiantes, concluindo que a formação de professores é apenas um conjunto de experiências fracamente coordenadas. Também comprovando carências na contínua formação do professorado, Nóvoa (1997) relata algumas "deficiências científicas" juntamente com "pobreza conceitual" de alguns programas de formação de professores, por se tratar de instrumentos de controle e manu- 
tenção dos interesses do Estado. Nas palavras do autor, as políticas reformadoras fomentam "[..] perspectivas sociais conformistas e orientações técnicas sobre o papel dos professores" (NÓVOA, 1997, p. 22), consequentemente, não proporcionam um desenvolvimento científico da profissão docente, tampouco contribuem para uma autonomia. Professoras entrevistadas por Giger (2004) consideraram ter tido uma formação inicial muito limitada e Gauthier et al. (1998) mostram que "uma crítica severa tem sido dirigida aos professores. [...] Também são criticados aqueles que os formam, ou seja, as faculdades de educação ou as instituições que exercem tarefa semelhante" (GAUTHIER, 1998, p. 32).

Com efeito, do ponto de vista de conteúdos de Astronomia, constantemente a literatura vem apontando a problemática da formação inicial de professores quanto ao acesso dos conhecimentos relacionados a esta ciência (BRETONES, 1999; MALUF, 2000; KANTOR, 2001; LANGHI; NARDI, 2007), levando-os a algumas situações gerais de despreparo: sensação de incapacidade e insegurança ao se trabalhar com o tema, respostas insatisfatórias para os alunos, falta de sugestões de contextualização, bibliografia e assessoria reduzida, e pouco tempo para pesquisas adicionais a respeito de tópicos astronômicos (LANGHI; NARDI, 2012), apesar de haverem propostas visando superar essas deficiências formativas (LEITE, 2006).

Para Pimenta e Anastasiou (2005), uma das soluções encontradas contra estas falhas da formação inicial é a formação continuada, que atinge especificidades e assume formatos diferenciados em relação aos seus objetivos, conteúdos, modalidades (presencial ou à distância, direta ou por meio de multiplicadores) e o tempo de duração, indo desde um curso rápido até programas que se estendem por vários anos. Ela tem se configurado em diferentes ações: cursos, oficinas, seminários e palestras que procuram atender às necessidades pedagógicas mais imediatas dos professores. Conforme os Referenciais para Formação de Professores (BRASIL, 2002), a formação continuada refere-se à formação de professores já em exercício, em programas promovidos dentro e fora das escolas, considerando diferentes possibilidades (presenciais ou à distância). A afirmação deste documento nos leva à interpretação de que a formação continuada parece se resumir à execução de cursos para professores, assumindo que sejam sinônimos.

Porém, de acordo com Sampaio (1998), os cursos e orientações técnicas que vêm sendo oferecidos crescentemente no âmbito da formação continuada não representam efetivas transformações na prática social dos professores. Em alguns casos, centram-se em uma formação voltada às suas práticas pedagógicas individuais, ao passo que os resultados efetivos são superficialmente dissolvidos no contexto da sala aula. Segundo Pietrocola (2005), cursos calcados unicamente em conteúdos não garantem mudanças significativas nas práticas docentes, enquanto cursos centrados em questões metodológicas da sala de aula podem contribuir mais efetivamente para isso. Conforme Pimenta (2000), muitos cursos que levam o nome de "formação continuada" não passam de meras atualizações de conteúdo, não alterando significativamente a prática docente. Para Mizukami et al. (2002), os cursos de curta duração (de 
30h a 180h) fornecem informações aos professores apenas para alterarem, às vezes, o seu discurso, de modo que contribuem muito pouco para uma mudança efetiva. Citando o exemplo de alguns cursos de curta duração, Garcia (1999) conclui que não provocaram qualquer efeito significativo nos seus participantes, sendo que "uma das críticas geralmente feita aos cursos de formação é a pouca incidência que têm na prática. Ou seja, os professores dificilmente aplicam ou incluem no seu repertório docente novas competências" (GARCIA, 1999, p. 34).

Porém, os referidos Referenciais (BRASIL, 2002) adverte que a formação continuada não deve ser considerada para sanar uma formação inicial de baixa qualidade, mas representa uma ação que envolve o desenvolvimento de competências dos professores de forma que lhes garantam condições reais do desenvolvimento de elementos transformadores em amplo diálogo com as mudanças educacionais. Assim, Langhi e Nardi (2012) apontam para a necessidade de elaborar ações de formação continuada voltados à inserção da Astronomia no contexto escolar de forma não propedêutica, de fato, por um sentido reflexivo de formação, priorizando por uma base teórica que proporcione uma análise crítica a respeito das condições concretas de inserção desta ciência no ensino.

Pensando em uma formação docente visando mudanças na sua prática de ensino, Zeichner (1993) mostra que o modelo formativo baseado na reflexão coletiva pode contribuir para o desenvolvimento profissional dos professores, pois se rejeita a ideia individualista de reflexão e incentiva os professores a se envolverem coletivamente e criticamente. Em outras palavras, o autor defende que a reflexão confere ao professor o exercício político e social de seu trabalho, não sendo restrito às questões práticas. Nesse caminho, o professor reflexivo, a partir de uma postura mais crítica e colaborativa entre os pares, pode compreender as relações emocionais, sociais e culturais que o espaço escolar demanda, pois este se encontra imerso em uma rede de relações com alunos, exigindo a deliberação de decisões democráticas e que atendam aos objetivos educacionais transformadores. O professor, nesta perspectiva, relaciona-se criticamente ao contexto social em que o aluno, os demais colegas de profissão e a escola pertencem. De fato, conforme o Ministério da Educação (MEC), os programas de formação continuada devem subsidiar a reflexão sobre a prática docente, com o exercício da crítica, bem como o aprofundamento da articulação dos componentes curriculares (BRASIL, 2008).

Portanto, é no contexto destas problemáticas e dos referenciais adotados que apresentamos a questão central desta pesquisa: Quais indicadores contribuem para uma formação de professores em Astronomia que resulte em uma mudança da sua prática profissional? Assim, o presente estudo objetivou investigar relatos de professores a fim de encontrar indicadores que contribuem para um modelo formativo docente, o qual resulte em mudanças em suas práticas de ensino ao inserirem temas ligados à Astronomia nas aulas.

\section{Contexto da pesquisa}

O Polo Astronômico Casimiro Montenegro Filho (PACMF), um dos espaços da Fundação Parque Tecnológico Itaipu (FPTI), localizado na cidade de Foz do Iguaçu/Paraná, 
tem como objetivo geral implementar ações de popularização das ciências, por meio da Astronomia e ciências correlatas. Esta instituição busca atuar na condição efetiva de um espaço cultural, turístico, educacional e científico, com foco na construção de uma cultura científica, por meio do estímulo à educação, à aquisição de conhecimentos e à busca de informações sobre determinado tema, fazendo com que estudantes, professores e turistas interajam, questionem, dialoguem, critiquem e pensem.

Entendemos o PACMF como um espaço não formal de educação, segundo referencias da área (GASPAR, 1993; JACOBUCCI, 2008; MARANDINO, 2008; BARROS; LANGHI; MARANDINO, 2018), onde pesquisadores, professores e outros profissionais trabalham com divulgação científica e onde é possível desenvolver atividades educativas e formação continuada de professores (VILAÇA; LANGHI; NARDI, 2013).

É neste contexto da articulação com a educação formal (escolar) e a formação continuada de professores em espaços não formais (não escolares) que o PACMF passou a ofertar, aos docentes das redes públicas, o curso "Fundamentos Teóricos e Metodológicos para o Ensino-Aprendizagem em Astronomia: Formação de Educadores”, em parceria com diversas instituições de ensino superior, diretorias de ensino, secretarias municipais de educação e núcleos de ensino. No período entre 2010 e 2016, o curso foi ministrado a 40 turmas de profissionais atuantes no Ensino Fundamental e no Ensino Médio, atendendo cerca de 1.700 professores. O curso apresenta a Astronomia apoiada nas Diretrizes Curriculares para a Educação Básica do Paraná e nos Parâmetros Curriculares Nacionais (PCN), proporcionando a reflexão sobre conceitos astronômicos e auxiliando os educadores em suas atividades educacionais interdisciplinares para despertar o interesse pela Astronomia, fomentar a cultura científica e favorecer o entendimento das tecnologias empregadas também em Ciências correlatas. O curso visa estimular e apoiar os processos de ensino e aprendizagem da Astronomia, com ações metodológicas a partir de um diálogo com as necessidades formativas demandadas pelos próprios professores, de conteúdo e de reflexão, trabalhando as concepções alternativas sobre fenômenos astronômicos. Atualmente o curso de formação de professores no PACMF possui a configuração conforme apresentada na tabela 1 .

Tabela 1: Configuração atual do curso para professores do PACMF.

\begin{tabular}{ll}
\hline $\begin{array}{c}\text { Carga } \\
\text { horária }\end{array}$ & \multicolumn{1}{c}{ Tema } \\
\hline $3 \mathrm{~h}$ & Recepção/Abertura do curso - Taxonomia do Universo \\
\hline $3 \mathrm{~h}$ & Astronomia nas Culturas \\
\hline $3 \mathrm{~h}$ & Evolução Estelar \\
\hline $3 \mathrm{~h}$ & Sistema Solar - Parte I \\
\hline $3 \mathrm{~h}$ & Sistema Solar - Parte II \\
\hline $3 \mathrm{~h}$ & Sistema Solar - Parte III \\
\hline $3 \mathrm{~h}$ & Lendo o Céu
\end{tabular}




\begin{tabular}{ll}
$3 \mathrm{~h}$ & Planeta Terra \\
\hline $3 \mathrm{~h}$ & Astronomia no Invisível \\
\hline $3 \mathrm{~h}$ & Planeta Terra (continuação) \\
\hline $3 \mathrm{~h}$ & Construção de Modelos e simuladores \\
\hline $3 \mathrm{~h}$ & Sistema Sol-Terra-Lua \\
\hline $3 \mathrm{~h}$ & Astronáutica e Ciências Espaciais \\
\hline $3 \mathrm{~h}$ & Pesquisa em ensino e contato com periódicos \\
\hline $5 \mathrm{~h}$ & Introdução à Gravitação Universal \\
\hline $12 \mathrm{~h}$ & $\begin{array}{l}\text { Relógios de Sol } \\
\text { Elaborar coletivamente um plano de aula sobre um dos temas abordados duran- } \\
\end{array}$ \\
$\begin{array}{l}\text { Encontros posteriores programados: SERIAs (Simpósio de Educadores Refle- } \\
\text { xivos para a Inserção da Astronomia) com o objetivo de refletir coletivamente } \\
\text { sobre sua prática de ensino de Astronomia, mediante comunicações orais pelos } \\
\text { professores relatando suas aulas, seguidas de momentos de reflexão e discus- } \\
\text { são durante 2,5 dias de evento, incluindo publicação de atas }\end{array}$
\end{tabular}

\section{Encaminhamentos metodológicos da pesquisa}

A presente pesquisa é de cunho qualitativo (BOGDAN e BIKLEN, 1994; ANDRÉ, 2005; FLICK, 2009). A investigação qualitativa em Educação assume várias formas e é conduzida em múltiplos contextos, segundo Bogdan e Biklen (1994). Ser qualitativo nas pesquisas presume o interesse primário em dados ricos em pormenores descritivos relativos a pessoas, locais e conversas. A pesquisa qualitativa em educação, conforme estes autores, ocorre sempre no sentido de haver mudanças, pois uma mudança é planejada, voluntária e tem como objetivo a inovação (por exemplo: os professores da amostra deste trabalho com potencial de mudanças em sua prática em relação à Astronomia após sua participação no curso em questão).

A constituição de dados ocorreu a partir de instrumentos tais como questionários e relatos de experiências de professores que participaram de várias edições dos cursos do PACMF. Os questionários abertos diagnósticos e avaliativos, elaborados segundo orientações de Gil (1996) e Flick (2009), possibilitaram o reconhecimento do perfil dos professores antes do início das suas atividades de formação no PACMF, bem como os aspectos avaliativos durante e após o processo. A partir das respostas aos questionários e após os encontros presenciais do curso, os professores eram conduzidos a elaborarem um plano de aula envolvendo um tema de Astronomia, com posterior aplicação em sua escola. Após a aula ministrada, os professores entregam um relato reflexivo da experiência vivenciada no formato de um trabalho final digitado de acordo com normas específicas. 
Encontros posteriores à aula ministrada propiciaram momentos de reflexão coletiva acerca de suas práticas de ensino, pois foram apresentadas como comunicações orais pelos próprios professores em eventos organizados para este fim, intitulados "Simpósio de Educadores Reflexivos para a Inserção da Astronomia” (I e II SERIA). Alguns destes relatos reflexivos foram também publicados no periódico "Informativo do Observatório Didático de Astronomia" (IODA), cujos trechos são aqui apresentados para exemplificar parte da análise de conteúdo efetuada na pesquisa. Assim, o corpus de análise neste trabalho são os artigos publicados pelos professores nas edições do IODA, ano de 2014, v. 2, n. 03 até o ano de 2016, v. 4, n. 04. Esses Simpósios são convergentes com o que propõem Moraes e Araújo (2012, p. 37) quando discutem os cursos de formação continuada e apontam que deve haver "avaliação permanente de seus reflexos nos espaços escolares, visando com que os estudos ali efetuados de fato tragam impactos positivos nos ambientes escolares".

A análise dos dados fundamentou-se nos procedimentos metodológicos da Análise de Conteúdo (BARDIN, 2009). A análise de conteúdo não se trata de um instrumento nem de uma única técnica: é um conjunto de técnicas de análise (BARDIN, 2009). Dentre este conjunto de técnicas, adotamos para esta pesquisa a vertente da Análise Categorial, por se adequar mais significativamente à tipologia de dados constituídos pelo nosso corpus de análise e por se enquadrar no objetivo central deste estudo. A partir da distribuição das unidades de registro, identificadas nos relatos dos professores, a análise permitiu colocar em evidência alguns índices e elaborar indicadores.

As unidades de registro podem ser palavras, frases ou temas, além de outros elementos. Em nosso estudo, as unidades de registro estão sublinhadas ao longo das transcrições dos relatos dos professores a fim de identificar cada unidade de base da análise. À medida que ocorria a exploração dos excertos, determinados temas foram emergindo, por serem explicitamente mencionados pelos sujeitos (alguns temas foram inferidos pelos pesquisadores), tornando-se os índices de nossa análise. A codificação dos índices, por sua vez, auxilia no estudo do conteúdo tanto nas dimensões qualitativas quanto quantitativas, principalmente mediante a contagem das frequências, pois a frequência com que um índice surge no texto é indicador de algum significado. "Uma vez escolhidos os índices, procede-se à construção de indicadores” (BARDIN, 2009, p. 126).

A partir desta fase de análise, os indicadores categorizáveis passam a fornecer um caráter mais interpretativo da mensagem subjacente contida nos relatos dos professores, superando a etapa descritiva da análise de conteúdo. São os indicadores que possibilitam ao analista elaborar inferências e constituir a "interpretação final fundamentada". Afinal, procuramos "conhecer aquilo que está por trás das palavras" (BARDIN, 2009, p. 44) do grupo de professores analisado.

Portanto, são estes indicadores encontrados em nossa análise que revelaram quais foram as contribuições decorrentes da vivência dos cursos para uma formação reflexiva dos 
professores e, como consequência destas reflexões, estes mudassem a sua prática profissional buscando pela inserção da Astronomia no contexto escolar, não de forma reprodutivista.

\section{Análise e resultados}

A fim de exemplificarmos as etapas da metodologia de análise e os resultados progressivamente constituídos, apresentamos no quadro 1 um trecho parcial das transcrições analisadas provenientes do corpus. Este quadro foi construído a partir dos procedimentos de preparação do material, na fase da leitura flutuante, conforme a metodologia adotada (BARDIN, 2009) e contém partes dos excertos discursivos dos professores P1 e P2 (os professores foram identificados por P1, P2, P3 e assim por diante). O material foi estruturado e alinhado estrategicamente para a identificação das unidades de registro (sublinhadas), os índices e a codificação, para sua posterior fase de análise: a exploração do material e o tratamento dos resultados (inferências).

De acordo com Bardin (2009), é na fase da Pré-análise que se faz a referenciação dos índices (coluna à direita do quadro 1), os quais podem ser menções a temas específicos da mensagem. Estes índices foram escolhidos a partir das unidades de registro demarcadas nas transcrições (sublinhados na coluna central do quadro 1) em conformidade com o objetivo desta pesquisa.

Quadro 01: Trecho do material de análise para exemplificação neste artigo.

\begin{tabular}{|c|c|c|}
\hline Cod. & $\begin{array}{c}\text { Excertos } \\
\text { (as unidades de registro estão sublinhadas) }\end{array}$ & Índices \\
\hline \multirow{4}{*}{$\begin{array}{l}\text { Jdah } \\
\text { Pff }\end{array}$} & & \multirow{3}{*}{$\begin{array}{l}\text { Gosto pessoal pela astro- } \\
\text { nomia }\end{array}$} \\
\hline & $\begin{array}{l}\text { Sempre gostei muito de Astronomia, mas na minha época de colé- } \\
\text { gio, não tínhamos as oportunidades que nossos estudantes têm }\end{array}$ & \\
\hline & hoje, inclusive, não podíamos falar nesse assunto e não nos era & \\
\hline & $\begin{array}{l}\text { falado. Acho importante colocarmos a disciplina de Astronomia } \\
\text { na grade curricular de nossas escolas, pois todos devem ter o direi- }\end{array}$ & Falhas na formação \\
\hline $\mathrm{Pd}$ & $\begin{array}{l}\text { to e o dever de conhecer e descobrir sobre nosso Universo. Antes } \\
\text { de fazer o curso eu achava que a história do Universo era realmen- } \\
\text { te como os meus professores me passaram e como eu estava pas- } \\
\text { sando para meus estudantes (totalmente errado). }\end{array}$ & Concepções alternativas \\
\hline Fmper & $\begin{array}{l}\text { O curso serviu para abrir meus olhos para as coisas como real- } \\
\text { mente elas são. Minhas aulas passaram a ser mais esclarecidas, }\end{array}$ & $\begin{array}{l}\text { Identificação de erros } \\
\text { conceituais }\end{array}$ \\
\hline & $\begin{array}{l}\text { divertidas, diversificadas e também muito curiosas. Vários outros } \\
\text { professores começaram a me procurar para tirar suas dúvidas e }\end{array}$ & $\begin{array}{l}\text { Contribuições do curso: } \\
\text { Mudanças na prática: }\end{array}$ \\
\hline $\mathrm{Pd}$ & $\begin{array}{l}\text { para saber como ensinar aos seus estudantes os termos corretos. } \\
\text { Não tive dificuldades em aplicar as aulas, pois as crianças se inte- } \\
\text { ressaram pelo assunto e também por ser um assunto que gosto }\end{array}$ & Falta de referências \\
\hline Jdah & $\begin{array}{l}\text { muito. Um dos obstáculos que enfrentei foi que assim que termi- } \\
\text { namos o curso tivemos em nossa escola duas semanas de festa }\end{array}$ & el de \\
\hline Jdah & literária e junto semana da criança. O tempo foi muito curto para & \\
\hline Poe & $\begin{array}{l}\text { realizarmos todas as atividades, mas conseguimos. } \\
\text { Tenho } 22 \text { anos de trabalho como professora e só trabalhei os con- }\end{array}$ & $\begin{array}{l}\text { Gosto pessoal pela Astro- } \\
\text { nomia }\end{array}$ \\
\hline
\end{tabular}




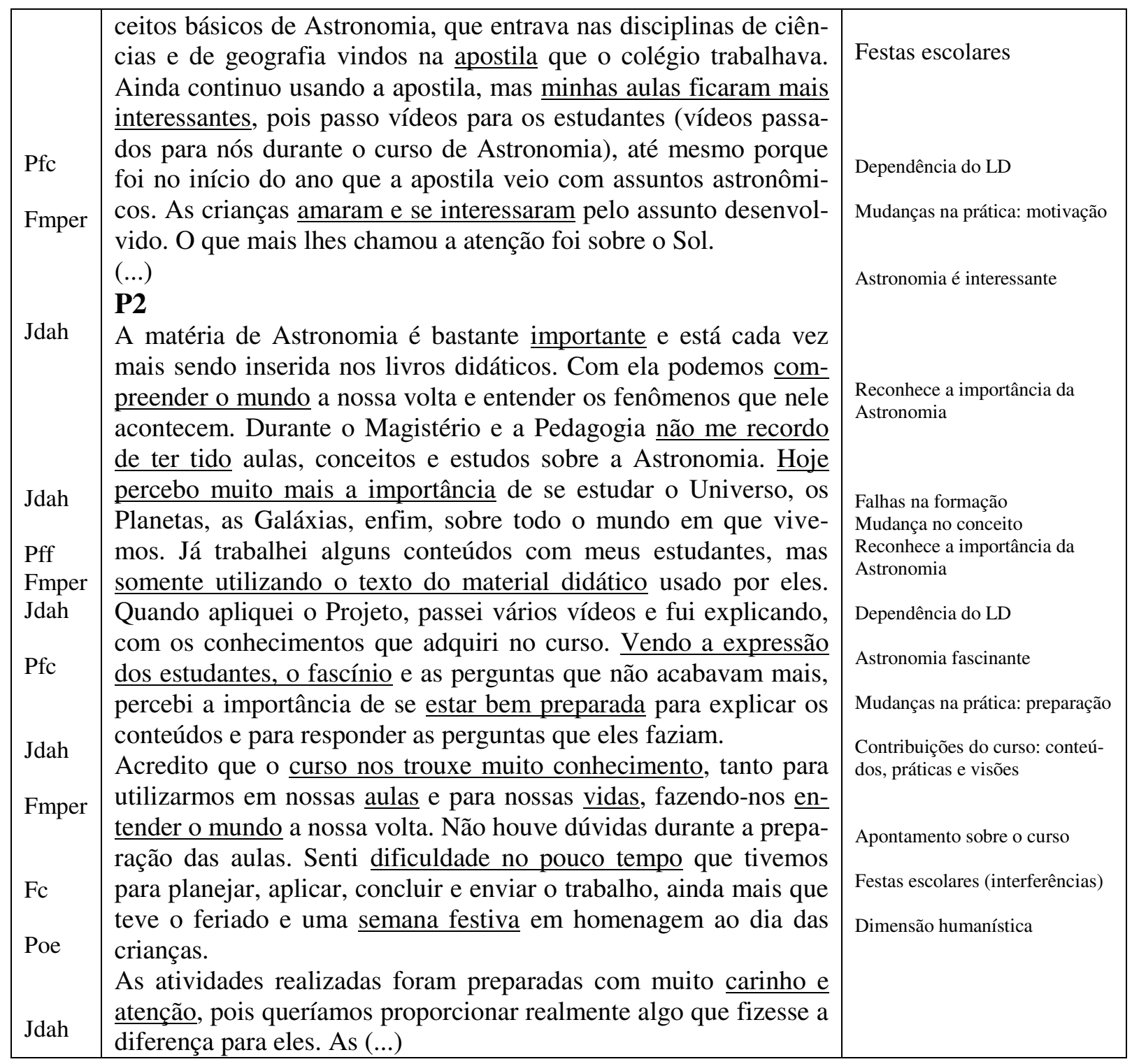

Na etapa seguinte, a Exploração do Material, (que visa superar a dimensão descritiva), procedemos às operações de fragmentação textual, categorização e codificação (primeira coluna do quadro 1). Sob o processo de diferenciação e reagrupamento das unidades de registro e seus índices correspondentes, algumas categorias foram emergindo de acordo com os critérios fundamentados nos objetivos desta pesquisa (semântico, por temáticas).

Assim, a partir destas operações, apresentamos os seguintes indicadores categorizáveis de acordo com as distribuições dos índices e sua frequência, sintetizado pelo quadro 2:

- Mudanças da prática de ensino resultantes da formação continuada reflexiva;

- Importância da Astronomia segundo as dimensões afetiva, humanística e curricular;

- Contribuições da ação de formação continuada; 
- Problemáticas do ensino da Astronomia: dificuldades para ensinar, falhas na formação, obstáculos externos, fontes confiáveis de consulta e pluralidade nas metodologias de ensino.

Quadro 02: Indicadores categorizados a partir dos índices.

\begin{tabular}{|c|c|c|}
\hline Codificação & $\begin{array}{c}\text { INDICADORES } \\
\text { CATEGORIAS E SUBCATEGORIAS }\end{array}$ & $\begin{array}{l}\text { ÍNDICES } \\
\text { (frequência) }\end{array}$ \\
\hline $\mathbf{J}$ & Justificativas para a inserção da Astronomia no ensino & 34 \\
\hline Jdah & Dimensão afetiva e humanística & 31 \\
\hline Jdc & Dimensão curricular & 3 \\
\hline $\mathbf{P}$ & Problemáticas do ensino da Astronomia & 44 \\
\hline $\mathbf{P d}$ & Dificuldades & 13 \\
\hline $\mathbf{P f c}$ & Fontes de consulta & 5 \\
\hline Pff & Falhas de formação & 12 \\
\hline Poe & Obstáculos externos & 7 \\
\hline PMe & Metodologias de ensino & 7 \\
\hline $\mathbf{F}$ & Formação continuada & 68 \\
\hline $\mathbf{F c}$ & Contribuições conteudistas e reflexivas & 18 \\
\hline Fmper & Mudanças da prática de ensino resultantes & 50 \\
\hline & TOTAL & 143 \\
\hline
\end{tabular}

Analisando as categorias e a frequência de seus índices correspondentes apresentadas no quadro 2, podemos afirmar que os discursos dos professores apontam primordialmente para a importância de oportunizar momentos de formação continuada (F) com abordagens reflexivas (não apenas conteúdos) como principal indicador de uma formação docente voltada para a mudança de sua prática com relação ao ensino de Astronomia. De fato, segundo Zeichner (1993), um modelo formativo baseado na reflexão coletiva possui grande potencial para o desenvolvimento de sua autonomia docente e consequente conscientização da necessidade de alterações em sua prática de ensino.

O acompanhamento do processo desta formação continuada e da produção textual dos professores acerca de suas experiências em sala de aula após o curso permitiu-nos inferir que eles passaram a compreender a importância da inserção da Astronomia no ensino (J) somente depois de vivenciarem momentos de reflexões coletivas sobre as justificativas para o ensino de Astronomia. Nota-se, em seus discursos, uma frequência maior das dimensões humanísticas e afetivas da Astronomia do que propriamente uma necessidade de ensiná-la simplesmente porque este conteúdo está no currículo. De fato, Langhi e Nardi (2014) demonstram a existência especificamente destas duas dimensões dentre as diversas justificativas para 
o ensino da Astronomia, conforme levantamento bibliográfico da produção acadêmica da área.

Por fim, a análise mostra que os professores, ao reconhecerem suas próprias limitações e a existência de problemáticas do ensino da Astronomia (P), sentem-se mais seguros para lidarem com suas dificuldades para ensinar, com limitações de sua formação inicial, com obstáculos externos, nas buscas de fontes confiáveis de consulta e na escolha de diferentes metodologias de ensino, diante da pluralidade que se apresenta.

Conforme Bardin (2009), a frequência com que um índice aparece no texto é um indicador de significações. Observando o quadro 2, é possível determinar o conjunto de indicadores em ordem decrescente da frequência de seus índices correspondentes e, respectivamente, seu grau de significação:

a) Reconhecimento da necessidade de mudanças da prática de ensino, com alterações efetivas da ação docente;

b) Dimensão afetiva e humanística da Astronomia;

c) Contribuições de conteúdos e reflexões por meio do curso;

d) Reconhecimento de suas dificuldades para o ensino de Astronomia;

e) Identificação de limitações na sua formação inicial em relação à Astronomia;

f) Lidar com obstáculos externos;

g) Usar diferentes metodologias de ensino;

h) Selecionar fontes de consulta confiáveis;

i) Analisar como a Astronomia está inserida no currículo.

Uma vez contemplado o objetivo de obter os indicadores das mensagens dos professores, estes nos permitiram produzir inferências relativas às condições de produção destes excertos. Conforme Bardin (2009), as inferências são operações pelas quais se admitem uma proposição em virtude da sua ligação com outras proposições já aceitas. São estas inferências que permitem avançar o tratamento do texto superando sua fase descritiva. Estamos procurando respostas à questão de pesquisa, as quais se encontram subjacentes aos discursos dos professores e, às vezes, não são tão evidentes.

Portanto, fundamentando-se nos procedimentos acima descritos, podemos afirmar como resposta ao nosso questionamento central que os indicadores contribuintes para uma formação de professores potencialmente transformadora são as seguintes inferências constituídas a partir da análise de conteúdo:

- Um modelo formativo docente sob abordagem reflexiva contribui para uma mudança da prática de ensino de Astronomia

- Refletir sobre a metodologia vigente de ensino que ele mesmo costuma abordar em sala de aula pode contribuir para a superação da mesma e possibilita a inserção de atividades diferenciadas. 
- Refletir sobre os conteúdos de Astronomia trabalhados até então por ele mesmo (ou não trabalhados) em relação aos conteúdos abordados pela formação continuada oferecida pode contribuir para que ele reconheça as suas concepções alternativas anteriores, as limitações de divulgação pela mídia, as fontes confiáveis de informação, os erros conceituais provavelmente ensinados até então e os erros presentes em livros didáticos (LANGHI; NARDI, 2012).

- Refletir sobre a sua formação cultural enquanto pessoa pode contribuir para que o professor altere a sua postura quanto ao ensino não só da Astronomia, mas quanto às suas práticas profissionais como um todo, potencializando mudanças que passam os limites de nível pessoal e provoquem alterações no Planejamento Pedagógico escolar local.

Por isso, conforme Nóvoa (1997) entende-se que foi possível proporcionar um espaço de interação em que as dimensões pessoais e profissionais dos professores dialogaram tanto em um sentido de construção de identidade profissional a partir da reelaboração de saberes de sua experiência com o de mudança curricular. Assim, a inserção da Astronomia no contexto escolar parte das deliberações profissionais dos professores e volta-se a elementos de transformações contextuais.

\section{- Reconhecer a importância do ensino de Astronomia devido às suas dimensões afetivas, humanísticas e curriculares, afetam as metodologias de trabalho do docente}

- Refletir sobre o senso comum de que "é importante ensinar conteúdos de Astronomia principalmente porque esta se encontra no currículo", associando isso à superação do intelectualismo e o conhecimento por si mesmo (normalmente apresentado sob um modelo formativo docente baseado em uma abordagem predominantemente conteudista e tecnicista nas universidades e escolas), pode contribuir para o desenvolvimento de aspectos exclusivos da mente humana, tais como: fascínio, admiração, curiosidade, contemplação, motivação, prazer, encantamento (LANGHI, 2016).

A Astronomia, neste contexto, permitiu problematizar enigmas da vida, proporcionando uma visão cosmológica das ciências e situando os sujeitos sobre o seu lugar no Cosmos. Nesse sentido, o contexto histórico e social em que conhecimentos astronômicos foram produzidos são aspectos que privilegiam a ligação entre o Homem e a Astronomia em uma dimensão humanística (KANTOR, 2012) que contribuíram para o desenvolvimento profissional e desenvolvimento pessoal destes professores (NÓVOA, 1997). Por isso, inferiu-se que o desenvolvimento pessoal esteve relacionado ao desenvolvimento profissional tendo como pano de fundo a reflexão sobre os aspectos humanísticos da Astronomia. 
- A ação de uma formação continuada de fato (não um curso exclusivamente conteudista de curta duração) pode proporcionar uma autoavaliação crítica sobre o seu desenvolvimento profissional

- Refletir sobre as diferenças existentes entre a situação formativa do professor antes, durante e após um processo de formação continuada (“como é, como deveria ser e como será a minha aula?”) pode contribuir para a validação e reconhecimento de seu crescimento profissional, permitindo que as mudanças ocorridas em sua prática docente tenham um caráter de constância, reconhecendo a necessidade da continuidade de sua formação em Astronomia, principalmente no que se refere aos aspectos pedagógicos. Nas palavras de Nóvoa (1997, p. 25) "estar em formação implica um investimento pessoal, um trabalho livre e criativo sobre os percursos e os projetos próprios, com vista à construção de uma identidade, que é também uma identidade profissional". Com isso, o processo reflexivo associado a um contexto muito próximo a realidade e necessidades dos professores, proporcionou-lhes autoria no sentido de uma autoformação crítica (NÓVOA, 1997).

- As mudanças na prática do professor são facilitadas quando o professor passa a se conscientizar da existência das principais problemáticas do ensino da Astronomia (dificuldades para ensinar, limitações na formação, obstáculos externos, escolha de fontes confiáveis de consulta e pluralidade nas metodologias de ensino)

- Refletir sobre suas dificuldades pessoais, profissionais e externas para o ensino de Astronomia e socializá-las com seus pares e com a instituição formadora pode contribuir para que o professor se encoraje a enfrentar estas problemáticas com mais propriedade e criticidade fundamenta em produções de literatura da área, sabendo que não está passando sozinho por estes obstáculos e que pode contar com o apoio externo à escola (em nosso caso o Polo Astronômico Casimiro Montenegro Filho). Com isso, as produções da área não foram traduzidas na prática destes professores, todavia, por meio de um diálogo reflexivo com o professor, problematizando a sua prática e os fatores que influenciam seu trabalho, atribuindo-lhe a autoria de sua formação profissional, identificou-se a reflexão crítica voltada a construção de autonomia para a sua autoformação (ZEICHNER, 1993).

Além destes indicadores, a categorização e subcategorização permitiram a identificação de uma sequência de três fases cronologicamente dispostas no processo formativo em Astronomia. Tal sequência não é claramente evidente nos discursos dos sujeitos e só puderam ser averiguados mediante a etapa final da Análise do Conteúdo, o tratamento dos resultados, quando elaboramos as inferências e interpretações (BARDIN, 2009). A esta sequência de fases inferidas por esta pesquisa, denominamos de "Etapas de superação do processo formativo em Astronomia", identificadas a seguir:

Etapa 1: O docente passa a reconhecer as dimensões humanísticas, afetivas e curriculares como justificativas para ensinar Astronomia, seja por meio de leituras de artigos cien- 
tíficos em periódicos da área, seja por meio de reflexões individuais ou coletivas (em suma: "sei que devo ensinar Astronomia").

Etapa 2: Uma vez reconhecida a importância de ensinar Astronomia, o professor passa a identificar problemáticas que podem interferir, dificultar e/ou impedir o professor de ensinar Astronomia (em suma: "não sei como ensinar Astronomia").

Etapa 3: Uma formação continuada sob abordagem reflexiva coletiva pode contribuir (profissionalmente e pessoalmente) para uma mudança de postura quanto ao ensino da Astronomia (em suma: "conseguirei ensinar Astronomia se eu buscar ajuda e mudar minha atitude atual").

O quadro 3 resume, portanto, a resposta à questão central desta pesquisa.

Quadro 03: Síntese dos indicadores que contribuem para uma formação reflexiva de professores e as etapas de superação do processo formativo em Astronomia.

\section{Indicadores que contribuem para formação docente em Astronomia}

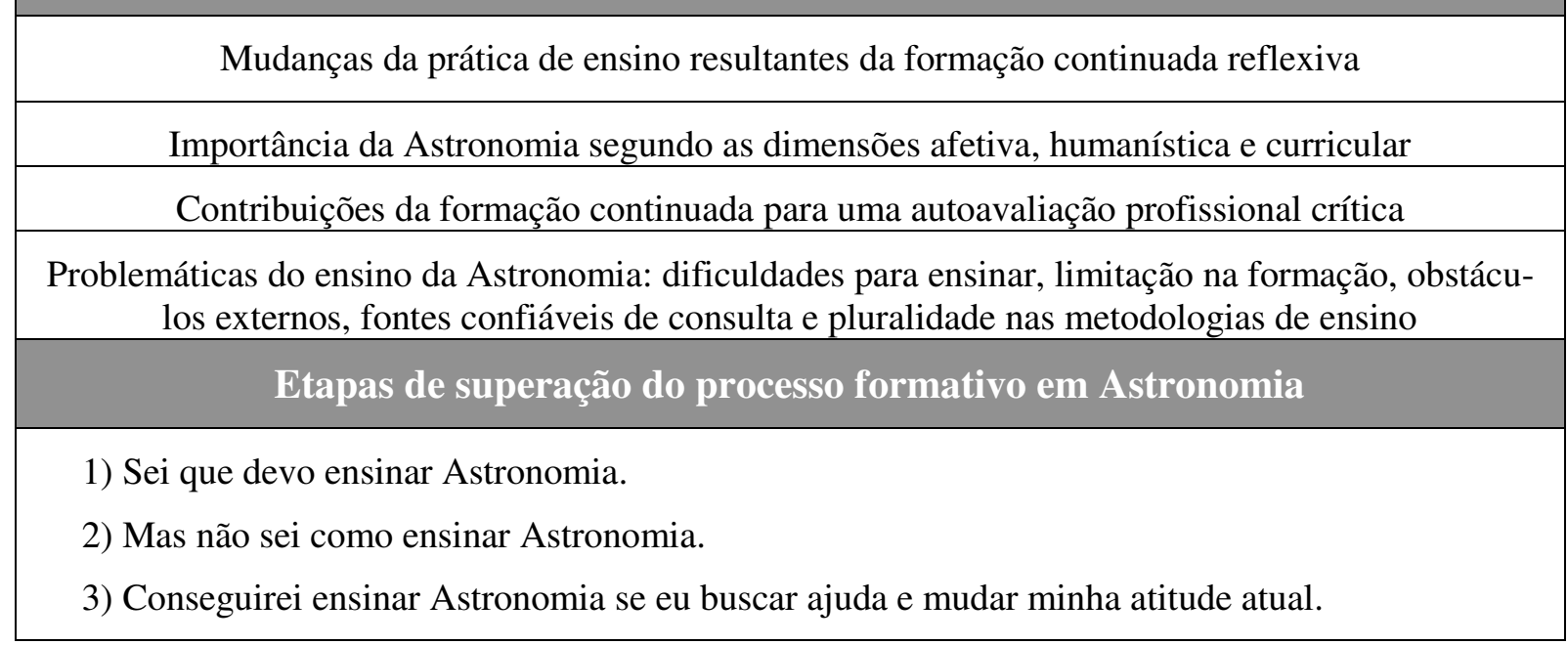

\section{Considerações}

Conforme os indicadores resultantes deste estudo apontam, o desafio da formação docente para a inserção da Astronomia na Educação Básica pode ser enfrentado com o uso do pleno potencial pedagógico que um Espaço Não-Formal de Ensino (em nosso caso, o Polo Astronômico) pode oferecer, desde que atue também na educação formal reflexiva, e não apenas para fins turísticos, de lazer ou de divulgação científica. As suas atividades e ações não estariam atendendo a estes desafios curriculares caso se embasassem única e exclusivamente na experiência pessoal de seus dirigentes, ou se seus "cursos para professores" possuírem uma abordagem unicamente conteudista, sem espaço para reflexão, verificação e avaliação da mudança da prática docente. 
Ressaltamos, portanto, a relevância do estabelecimento de parcerias destes espaços não escolares com pesquisadores de Educação em Astronomia. Deste modo, há a sustentabilidade do processo, no sentido de estes ambientes atuarem não apenas enquanto locais do ensino formal e não-formal, mas também enquanto ambiente de pesquisa, fornecendo-lhe retornos constantes para melhorias do próprio atendimento, além de possibilitar a construção de conhecimento científico para a área de Ensino.

\section{Referências}

ANDRÉ, M. Pesquisa em educação: questões de teoria e de método. In: ENCONTRO NACIONAL DE PESQUISA EM EDUCAÇÃO EM CIÊNCIAS, 5, 2005, Bauru. Atas... Bauru: ABRAPEC, p. 1-12, 2005.

BARDIN, L. Análise de Conteúdo. Lisboa, Portugal; Edições 70 Ltda, 2009.

BARROS, L. G.; LANGHI, R.; MARANDINO, M. A investigação da prática de monitores em um observatório astronômico: subsídios para a formação. Revista Brasileira de Ensino de Física, v. 40, n. 3, e3405, 2018.

BOGDAN, R. C.; BIKLEN, S. K. Investigação qualitativa em educação. Porto, Portugal, 1994.

BRASIL. Ministério da Educação. Secretaria de Educação Fundamental. Referenciais para formação de professores. Brasília: MEC, 2002.

BRASIL. Ministério da Educação. Secretaria de Educação Básica. Rede nacional de formação de professores. Brasília: MEC, 2008.

BRETONES, P. S. Disciplinas introdutórias e Astronomia nos cursos superiores do Brasil. 1999. 187 f. Dissertação (Mestrado) - Instituto de Geociências, UNICAMP, Campinas.

LEITE, C. Formação dos professores de Ciências em Astronomia: uma proposta com enfoque na espacialidade. 2006. Tese (Doutorado) - Faculdade de Educação, Universidade de São Paulo. Disponível em: <http://www.teses.usp.br/teses/disponiveis/48/48134/tde05062007-110016/>.

FLICK, U. Introdução à pesquisa qualitativa. Porto Alegre: Artmed, 2009.

GARCIA, C. M. Formação de professores: para uma mudança educativa. Portugal: Porto Editora, 1999.

GASPAR, A. Museus e centros de Ciências: conceituação e proposta de um referencial teórico. 1993. Tese (Doutorado) - São Paulo, USP. 
GAUThier, C.; MARTINEAU; S.; DESBIEnS, J.; LiMA, F. P.; MALO, A. Por uma teoria da pedagogia: pesquisas contemporâneas sobre o saber docente. Ijuí/BRA: Editora UNIJUI, 1998.

GIGER, I. P. O discurso do professor sobre sua própria ação: questões metodológicas da entrevista. In: MACHADO, A. R.(Org). O ensino como trabalho: uma abordagem discursiva. Londrina: Eduel, 2004.

GIL, A. C. Como elaborar projetos de pesquisa. 3. ed. São Paulo: Atlas, 1996.

JACOBUCCI, D. F. C. Contribuições dos espaços não-formais de educação para a formação da cultura científica. Em extensão, Uberlândia, v. 7, p. 55-66, 2008.

KANTOR, C. A. A ciência do céu: uma proposta para o ensino médio. 2001. Dissertação (Mestrado em Ensino de Ciências) - Instituto de Física, USP, São Paulo.

KANTOR, C. A. Educação em Astronomia sob uma perspectiva humanístico-científica: a compreensão do céu como espelho da evolução cultural. 2012. Tese (Doutorado) - Faculdade de Educação, Universidade de São Paulo, São Paulo.

LANGHI, R.; NARDI, R. Ensino de Astronomia: erros conceituais mais comuns presentes em livros didáticos de ciências. Caderno Brasileiro de Ensino de Física, v. 24, n. 1, p. 87-111, abr. 2007.

LANGHI, R.; NARDI, R. Educação em Astronomia: repensando a formação de professores. São Paulo: Escrituras, 2012.

LANGHI, R.; NARDI, R. Justificativas para o ensino de Astronomia: o que dizem os pesquisadores brasileiros? Revista Brasileira de Pesquisa em Educação em Ciências, v. 14, n. 3, p. 41-59, 2014.

LANGHI, R. Aprendendo a ler o céu: pequeno guia prático para a astronomia observacional. 2 ed. São Paulo: LF Editorial, 2016.

MALUF, V. J. A Terra no espaço: a desconstrução do objeto real na construção do objeto científico. 2000. 141 f. Dissertação (Mestrado em Educação) - UFMT, Cuiabá.

MARANDINO, M. (Org.). Educação em museus: a mediação em foco. São Paulo: GEENF/ FEUSP, 2008.

MIZUKAMI, M. G. N. et al. (Org). Escola e aprendizagem da docência: processos de investigação e formação. São Carlos: EdUFSCar, 2002.

MORAES, J. U. P.; ARAÚJO, M. S. T. O Ensino de Física e o Enfoque CTSA: Caminhos para uma educação cidadã. São Paulo: Editora Livraria da Física, 2012. 
NÓVOA, A. Formação de professores e profissão docente. In: NÓVOA, A. (Org.) Os professores e a sua formação. 3. ed. Lisboa: Dom Quixote, 1997.

PIETROCOLA, M. Construção e realidade: o papel do conhecimento físico no entendimento do mundo. In: PIETROCOLA, M. (org.) Ensino de física: conteúdo, metodologia e epistemologia em uma concepção integradora. 2. ed. Florianópolis: Editora da UFSC, 2005.

PIMENTA, S. G. Formação de professores: identidade e saberes da docência. In: PIMENTA, Selma Garrido (Org). Saberes pedagógicos e atividade docente. 2. ed. São Paulo/BRA: Cortez, 2000.

PIMENTA, S. G.; ANASTASIOU, L. G. C. Docência no ensino superior. São Paulo: Cortez, 2005.

SAMPAIO, M. M. F. Um gosto amargo de escola. Relações entre currículo, ensino e fracasso escolar. São Paulo: Educ/FAPESP, 1998.

VILAÇA, J.; LANGHI, R.; NARDI, R. Planetários enquanto espaços formais/não-formais de ensino, pesquisa e formação de professores. In: ENCONTRO NACIONAL DE PESQUISA EM EDUCAÇÃO EM CIÊNCIAS, 9, 2013, Águas de Lindoia. Atas... São Paulo: ABRAPEC, p.1-8, 2013.

ZEICHNER, K. A formação reflexiva de professores: ideias e práticas. Lisboa: EDUCA, 1993.

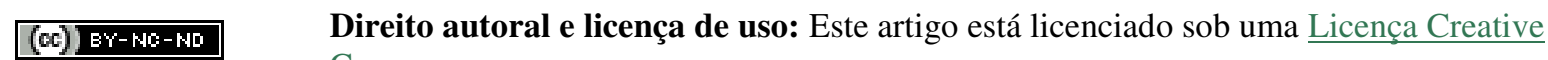
Commons. 